Святковская Е.А., Тростенюк Н.Н., Салтан Н.В., Гонтарь О.Б.

12. Аврорин Н.А. Чем озеленять города и поселки Мурманской области и северных районов КарелоФинской ССР. Кировск: Испол. ком. Мурманского обл. сов. депутатов трудящихся, 1941. 124 с.

13. Озеленение городов и поселков Мурманской области. Практическое руководство. Мурманск: Книжное изд-во, 1982. С. 60-86.

14. Тростенюк Н.Н., Святковская Е.А. Декоративные многолетники для озеленения городов Кольского Севера // Ботанические сады России: история, место и роль в развитии современного общества: тез. докладов и сообщений научно-практической конференции, посвящ. 270-летию Соликам. ботан. сада Григория Демидова, 25-26 авг. 2001 г. Соликамск, 2001. С. $165-166$.

15. Гонтарь О.Б., Жиров В.К., Казаков Л.А., Святковская Е.А., Тростенюк Н.Н. Зеленое строительство в городах Мурманской области. Апатиты: Изд-во Кольского научного центра РАН, 2010. 224 с.
16. Семко А.П., Святковская Е.А., Маслюкова Т.А. Агрофизические и агрохимические свойства почв для зеленых насаждений в некоторых населенных пунктах Мурманской области // Агротехника декоративных растений на Севере. Апатиты: Изд-во КФ АН CCCP, 1988. C. 74-88.

17. Тростенюк Н.Н., Святковская Е.А., Носатенко О.Ю., Гонтарь О.Б. Основные этапы создания ассортимента декоративных многолетников для оптимизации урбанизированных территорий Кольского Севера // Биоразнообразие и культуроценозы в экстремальных условиях: сборник материалов 4-й всероссийской научной конференции с международным участием, посвященной 85-летию ПАБСИ КНЦ РАН. 26-28 октября 2016 г., г. Апатиты-Кировск, Российская Федерация / отв. ред. И.В. Калашникова. Апатиты, 2016. С. 79-82.

18. Аврорин Н.А., Андреев Г.Н., Головкин Б.Н., Кальнин А.А. Переселение растений на Полярный Север. Ч. 1. М.-Л.: Изд-во АН СССР, 1964. 86 с.

\title{
ANALYSIS AND WAYS TO EXPAND THE SPECIES DIVERSITY OF THE ASSORTMENT OF PERENNIAL HERBACEOUS FLOWERING PLANTS FOR LANDSCAPING URBAN AREAS OF THE KOLA POLAR REGION
}

(C) 2018

Sviatkovskaya Ekaterina Alexandrovna, researcher of Plant Introduction and Acclimatization Laboratory

Trostenyuk Nadezhda Nikolaevna, researcher of Plant Introduction and Acclimatization Laboratory

Saltan Natalya Vladimirovna, candidate of biological sciences,

researcher of Plant Introduction and Acclimatization Laboratory

Gontar Oksana Borisovna, candidate of biological sciences, acting director

N.A. Avrorin Polar-Alpine Botanical Garden-Institute of Kola Scientific Centre of Russian Academy of Sciences (Apatity, Murmansk Region, Russian Federation)

\footnotetext{
Abstract. The paper analyzes the selection of species of perennial herbaceous flowering plants to enrich the existing range in the landscaping of the cities of the Kola Polar region. The selection of the assortment of perennials for landscaping of the cities was carried out by the Polar-Alpine Botanical garden institute for the first time. Currently, the assortment of perennial flowering plants has enriched and it is represented by 115 species in 28 families. New species have a high decorative value, stability and passed a long period of tests on collection nurseries and in urban conditions. Analysis of the existing range and the study of the results of long-term tests of various plants in nature provide an opportunity to identify the main families and species, whose representatives have a high decorative value and stability in the Far North. Families Primulaceae and Rosaceae Juss are the most promising to replenish the landscaping assortment. When forming the assortment, the number of species is very important as well as their ratio in different groups by flowering period, color tone and height. As the analysis of species diversity showed, it is necessary to increase the early-flowering perennials, especially with yellow-orange and purple-red shades of flowers. It has been noted that the percentage of border plants with compact shrubs was low. In the existing assortment, the positive aspect is the balance of warm and cold tones. Due to the resistance to the harsh climatic and environmental conditions of the Kola North perennial herbaceous plants are perspectives for landscaping the cities of the Kola Subarctic.

Keywords: assortments of perennial herbaceous flowering plants; ways to expand species diversity; perspectives of introduction; collection funds and nurseries of Polar-Alpine Botanical Garden; stability and decorativeness of perennials; landscaping; urban areas; Kola Subarctic.
}

\section{СООТНОШЕНИЕ ПОЛОВ И ФАКТОРЫ ИЗМЕНЕНИЯ ЧИСЛЕННОСТИ ЛИСИЦЫ ОБЫКНОВЕННОЙ НА ТЕРРИТОРИИ КРАСНОАРМЕЙСКОГО РАЙОНА САМАРСКОЙ ОБЛАСТИ}

(C) 2018

Склюева Ольга Александровна, аспирант кафедры экологии и охраны окружающей среды Склюев Валерий Витальевич, кандидат биологических наук, декан химико-биологического факультета Хакимов Рафик Ибрагимович, проректор по безопасности Самарская государственная областная академия (Наяновой) (2. Самара, Российская Федераиия)

Аннотация. В статье приведены данные по соотношению полов лисицы обыкновенной (Vulpes vulpes, Linnaeus, 1758) на территории Красноармейского района Самарской области. По результатам зимних троп- 
лений следов млекопитающих с картированием местности показано размещение индивидуальных участков самцов и самок, рассмотрена связь между динамикой численности, половозрастным составом и размещением индивидуальных участков. Рассмотрены некоторые аспекты поведенческих адаптаций и причины изменения численности животных исследуемой территории. Описано влияние фактора браконьерства на динамические показатели исследуемой популяции и возможную опасность развития эпизоотического процесса. Проведен сравнительный анализ с ранее полученными данными по соотношению самцов и самок в помете. В работе указывается на возможные причины изменения численности животных исследуемых территорий (показано как влияние антропогенного фактора, так и полоспецифики, в частности - особенности выбора индивидуальных участков самками и самцами). Браконьерство оказывает прямое влияние на механизмы поддержания гомеостатического состояния исследуемой популяции. Также приводится прогноз влияния браконьерства на ухудшение эпидемиологической и эпизоотической ситуации в исследуемом регионе. В работе даны рекомендации по уменьшению возможного ущерба для хозяйственной деятельности человека.

Ключевые слова: динамика численности; соотношение полов; популяция; лисица обыкновенная (Vulpes vulpes); половой диморфизм; соотношение самцов и самок; колебания численности; индивидуальный участок; браконьерство.

\section{Введение}

Рациональное использование ресурсов среды предусматривает определенное ограничение плотности, закономерную дисперсию особей в пространстве. С целью понимания интенсивности процессов, происходящих в популяции, важно иметь представления о полоспецифической динамике изучаемой совокупности особей и факторах, оказывающих влияние на колебания численности.

Задачей исследования явилось определение соотношения полов лисицы обыкновенной на территории Красноармейского района Самарской области и причин колебания численности животных исследуемой территории, описание характера влияния фактора браконьерства на колебания численности животных и опасность эпизоотии на примере животных исследуемой территории.

Исследование проводилось в окрестностях села Воздвиженка Красноармейского района Самарской области в зимнее время года. Территория исследования представляет степной ландшафт, используется как сельскохозяйственные угодья, граничит с лесопосадкой, включает трассу федерального значения, проселочные дороги и село Воздвиженка. Многочисленны овражки на примыкающих к селу территориях.

\section{Объект и методы исследований}

Объект исследования: популяция лисицы обыкновенной (Vulpes vulpes, Linnaeus, 1758). В качестве методологической основы исследований была использована методика детальных троплений следов млекопитающих в зимний период времени (на основе работ А.Н. Формозова [1; 2], Н.Н. Руковского [3], П.Г. Ошмарина, Д.Г. Пикунова [4], Д.П. Мозгового [5]). Метод тропления зимних наследов животных позволяет изучить численность, распределение по территории, размеры индивидуальных участков, а также общие навыки выживания в антропогенной среде обитания [6;7].

\section{Результаты исследований и их обсуждение}

При анализе полученных данных были получены различия в динамике численности самцов и самок лисицы обыкновенной. В частности, были показаны более резкие колебания численности самцов и более плавный график колебания численности самок. Также можно отметить, что наблюдается увеличение численности самок с зимнего периода времени 20012002 гг. до 2008-2009 гг. (рис. 1).

На графике также можно видеть численное преобладание самок. И лишь в снежные периоды 20012002 г. и 2008-2009 гг. численность самцов и самок выравнивалась, что возможно, если количество рожденных самцов несколько превосходит число рожденных самок. Таким образом, соотношение полов в целом соответствовало: 1:2 (самки, самцы) в 20002001 гг.; 1:1 - 2001-2002 гг.; 1:1,35 - с 2002-2003 гг. по 2007-2008 гг.; 1:1 - в 2008-2009 гг.; 1:2,75 - в 2009-2010 гг. [8].

Интересно отметить, что самки выбирают участки с наиболее разнообразными условиями, предпочитая участки с овражками. Зачастую эти участки граничат с лесопосадками или находятся на границе сельхозугодий (рис. 2).

В ряде литературных источников показано достоверное отклонение доли рожденных самцов по отношению к самкам от соотношения (1ळ : 19$)$ не только на основании суммарных данных за 10 лет, но и по отдельным годам, что, в частности, хорошо согласуется с результатами исследования изолированной дикой популяции лисицы в районе г. Магдебурга [9] (среди новорожденных животных в 33 выводках (153 щенка) доля самцов составила 56,4\% [9]) и при анализе полового состава бернских лисиц [10]. Также при анализе 3226 пометов серебристо-черных лисиц в течение ряда лет (данные для промышленного разведения) было показано, что самцы в пометах составляют в среднем 54,6\% всех новорожденных; этот показатель изменялся незначительно по годам от 52 до $56,1 \%$ [11; 12]. Интересно отметить, что при этом пик достоверности преобладания самцов над самками наблюдался в пометах самцов 2-4-летнего возраста и самок 1-4-летнего, у матерей 3-4-летнего возраста - наблюдается увеличение доли родившихся самок в помете [12]. Важно отметить, что достоверность отклонения наступает и обрывается резко, без переходов, причем средняя доля самцов остается почти постоянной при разной величине помета [12]. Данная закономерность влияния возрастных различий на преобладание самцов в помете хорошо согласуется с полученными нами данными (см. график на 
рис. 1). Именно при подобном распределении самцов и самок в помете становится возможной ситуация по выравниванию численности животных различных половых групп на исследуемой территории в зимний период 2001-2002 и 2008-2009 годов. При проведении анализа динамики численности самцов можно видеть, что они быстрее восстанавливают свою численность к 2001-2002 и 2008-2009 годам. Это возможно только при преобладании количества самцов над самками в помете. Однако приведенные данные не противоречат и утверждению о преобладании самок в популяции, восстанавливающей численность. Тем более что самки данной территории обеспечивают быстрое восстановление численности при том, что доля самцов в пометах может быть выше самок, об этом свидетельствует динамика численности самцов на нижнем графике - рис. 1, что может быть объяснено их большим количеством в помете, что, в свою очередь, хорошо согласуется с литературными данными о половом соотношении потомства [12].



Годы проведения исследований

Рисунок 1 - Динамика численности лисицы обыкновенной исследованных территорий

По нашим наблюдениям, самки реже гибнут в результате отстрела (носящего браконьерский характер). Сельхозугодья на данной территории представляют собой обширные открытые пространства (летом засеянные монокультурой); зимой наиболее благоприятны для охоты, в том числе и с использованием снегоходов. Возможно, свою роль играет как уда- ленность участков, предпочитаемых самками, так и особенности самих участков (зачастую это участки с овражками), т.е. играет роль предпочтение самками территорий с максимально разнообразными эдафическими условиями (именно такие территории оказываются наименее пригодными для передвижения с использованием снегохода) (рис. 2).
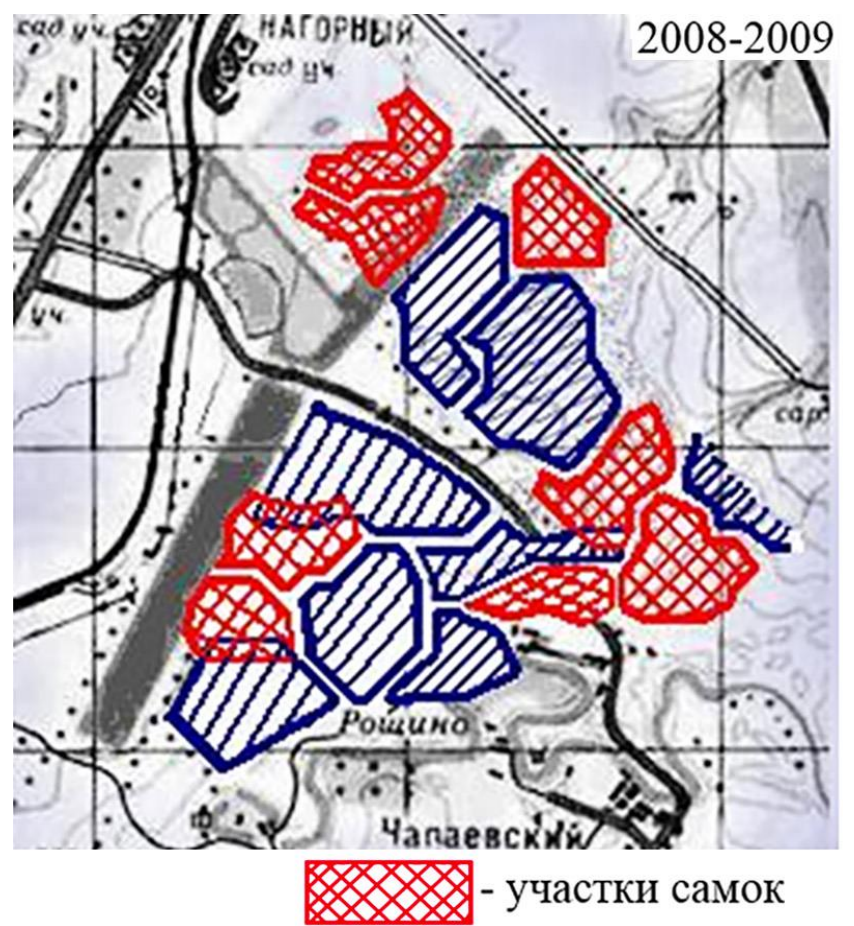
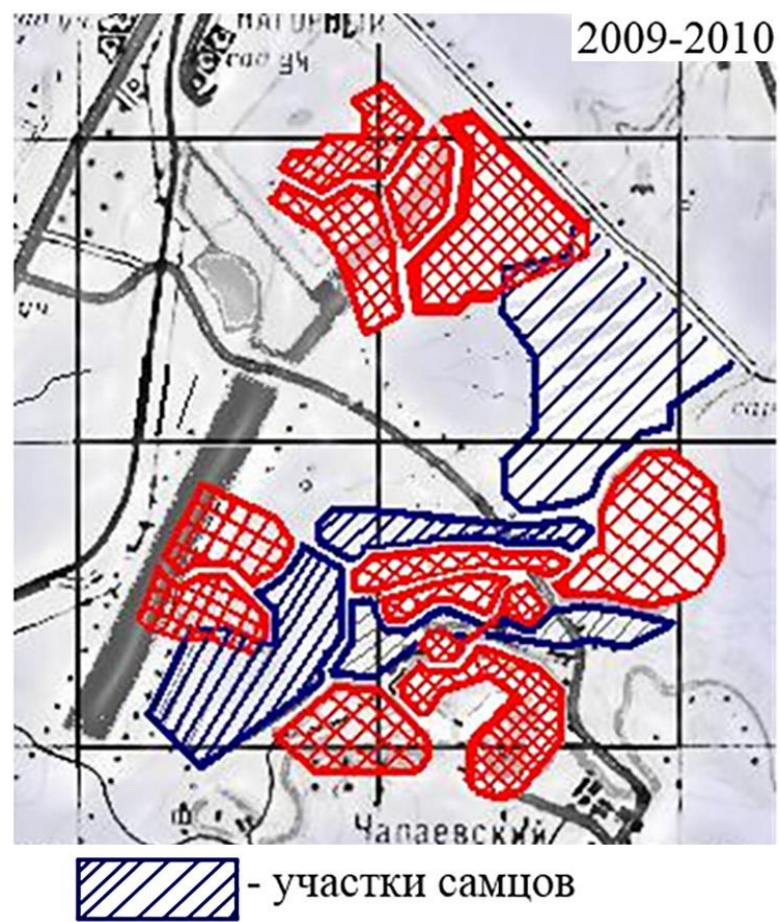

Рисунок 2 - Расположение индивидуальных участков на территории исследования (по [8])

Возможно, именно браконьерство способствует колебаниям численности как в сторону снижения (это очевидно), так и в сторону резкого увеличения, что, в сою очередь, хорошо согласуется с рядом публикаций В.А. Геодакяна [13-15], где указывается на связь между различиями полоспецифических дина- 
мик численности и эволюционной пластичностью вида (больше самцов - пластичнее популяция). При этом большая дисперсия мужского пола по всем признакам приводит к тому, что первыми жертвами всех неблагоприятных факторов среды оказываются самцы [13-15], что также хорошо согласуется с графиком по результатам исследований (см. рис. 1), кроме того, на наш взгляд, большую роль играет поведенческие аспекты жизнедеятельности (выбор индивидуального участка, допуск самок на свою территорию, в результате чего, даже в изначально равных условиях, молодая самка будет иметь некоторое преимущество). Также интересно отметить в данном ключе расположение индивидуальных участков самцов и самок лисицы (см. рис. 2), в особенности в связи с повышением рождаемости самцов в 20002001 гг., с 2002-2003 гг. по 2007-2008 гг. и в 20092010 гг.

Со временем из-за высокой смертности самцов меняется соотношение полов в популяции (это хорошо видно на рис. 1 для 2009-2010 годов). В этом случае, согласно работам В.А. Геодакяна [13; 14], популяции надо восполнить повышенную смертность самцов ростом их рождаемости. Таким образом происходит рост и смертности, и рождаемости самцов, т.е. повышается их «оборачиваемость» [1315]. Однако полученные в результате проведенных исследований данные не противоречат и описанной в литературе [16] ситуации преобладания самок, когда популяция восстанавливает свою численность.

Кроме того, интересно отметить вспышки численности мышевидных грызунов (появившиеся после изменения агротехнических мероприятий), составляющих основную кормовую базу лисицы исследованной территории [17], что также может вести к перенаселению угодий, в том числе прилегающих к деревне, и в разы повышает как вероятность эпизоотий в виде бешенства (характерно для данной территории), так и (в случае вспышки) вероятность нападения на домашних животных и человека. Можно сделать предположение, что нормальные компенсаторные механизмы ограничения численности [12] на данной территории не работают. Фактором, определяющим динамику численности, на наш взгляд, является антропогенный, действующий как посредством изменения агротехники, так и непосредственно - через браконьерство. Чтобы проиллюстрировать данную зависимость, нами была построена схема (рис. 3).

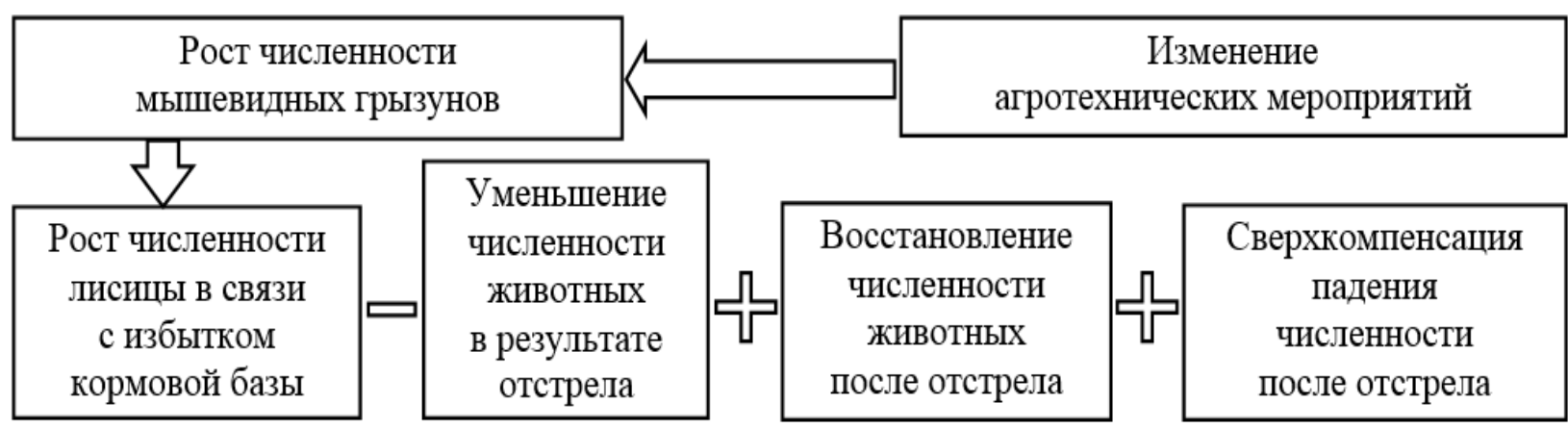

Рисунок 3 - Схема изменения интенсивности прироста лисиц для исследованной территории

в Красноармейском районе Самарской области

Если прирост условно принять за 1 (как и убыль), вследствие единичного фактора прироста-убыли, то: $1-1+1+1=+2$ будет равен получившийся прирост животных данной территории (рис. 3). Стоит отметить, что блок-схема на рис. 3 является иллюстрацией изменения динамики численности (по рис. 1) и хорошо дополняет описание причин, лежащих в основе наблюдаемого на рис. 2 расположения индивидуальных участков. Именно браконьерство, по нашим наблюдениям, в совокупности с миграциями животных исследованных территорий к деревне, увеличивает опасность заболеваний домашних животных и человека.

В заключение стоит отметить, что с целью поддержания плотности популяции лисицы на оптимальном уровне, охотхозяйствам рекомендуется ограничивать численность лисиц до 1 особи на 3 км $^{2}$ [8], при отсутствии скачкообразного изменения численности в связи с незаконным отстрелом. Стоит отметить, что автор в целом категорически против вмешательства в регуляцию численности природных популяций, но ряд действующих в отношении иссле- дуемой совокупности особей факторов делает нежелательную рекомендацию возможной.

\section{Выводы}

1. Соотношение полов лисицы различалось по годам: от 1:2 (самки:самцы) - в 2000-2001 гг. до 1:1 2001-2002 гг.; 1:1,35 - в 2002-2003 гг. и 2007-2008 гг.; к 1:1 - в 2008-2009 гг. и 1:2,75 - зимой 20092010 гг. Колебания численности животных исследуемых территорий объясняются как антропогенным фактором, так и полоспецификой (в частности, особенностями выбора индивидуальных участков самками и самцами).

2. Браконьерство оказывает прямое влияние на механизмы поддержания гомеостатического состояния исследуемой популяции и ведет к ухудшению эпизоотической ситуации в исследуемом регионе.

\section{Список литературы:}

1. Формозов А.Н. Снежный покров как фактор среды, его значение в жизни млекопитающих и птиц СССР 2-е изд. / отв. ред. Е.Н. Матюшкин. М.: Изд-во МГУ, 1990. $287 \mathrm{c}$. 
2. Формозов А.Н. Спутник следопыта. М.: Изд-во МГУ, 1989. 320 с.

3. Руковский Н.Н. По следам лесных зверей. 2-е изд., перераб. М.: Агропромиздат, 1988. 175 с.

4. Ошмарин П.Г., Пикунов Д.Г. Следы в природе. М.: Наука, 1990. 294 с.

5. Мозговой Д.П. Экологические особенности популяций млекопитающих и организация учетов численности // Всесоюзное совещание по проблеме кадастра и учета животного мира. Уфа: АН СССР, 1989. С. 327-328.

6. Камалова Е.С., Мартынова В.В., Фокина М.Е. Биотопическое распределение енотовидной собаки на территории Самарской области // Вестник Тамбовского университета. Серия: естественные и технические науки. 2016. Т. 21, № 5. С. 1763-1767.

7. Новиков Г.А. Полевые исследования экологии наземных позвоночных животных. М.: Сов. наука, $1949.567 \mathrm{c}$.

8. Склюев В.В. Популяционный анализ лисицы обыкновенной (Vulpes vulpes) в биотопах Самарской области разной степени нарушенности: дис. ... канд. биол. наук. Самара, 2010. 220 с.

9. Stubbe M. Zur populationsbiologie des rotfuchses Vulpes vulpes (L.) // Hercinia. 1967. B. 4, № 1. P. 1-10.

10. Wandeler A. Einige daten uber den berischen fuchsestand // Rev. Suisse Zool. 1968. Vol. 75, № 4. P. 1071-1075.

\section{RED FOX SEX RATIO AND CHANGES IN THE NUMBER IN THE KRASNOARMEISKY DISTRICT OF THE SAMARA REGION}

(C) 2018

Sklueva Olga Aleksandrovna, postgraduate student of Ecology and Environmental Protection Department Sklyuev Valeriy Vitalyevich, candidate of biological sciences, head of Chemistry and Biology Department

Khakimov Rafik Ibragimovich, prorector for security

Samara State Regional Academy (Nayanova) (Samara, Russian Federation)

Abstract. The paper presents some data on the red fox (Vulpes vulpes, Linnaeus, 1758) sex ratio in the Krasnoarmeysky District of the Samara Region. The results of winter trails traces of mammals show the placement of individual sites of males and females. The authors consider relationship between the population dynamics, sex and age composition and the placement of individual sites. Some aspects of behavioral adaptations and causes of changes in the number of animals in the study area are considered. The influence of a poaching factor on the dynamic indicators of the studied population and the possible danger of the epizootic process is described. A comparative analysis with the previously obtained data on the ratio of males and females in the litter is carried out. The paper indicates possible causes of animals number changes in the study areas. Poaching has a direct impact on the studied population homeostatic state maintaining mechanisms. There is also a forecast of poaching influence on deterioration of epidemiological and epizootic situation in the investigated region. In this paper we give recommendations to minimize possible damage by human activities.

Keywords: population dynamics; sex ratio; population; common red Fox (Vulpes Vulpes); sexual dimorphism; sex ratio of males and females; fluctuations in population size; individual habitat; poaching.

\section{ОСОБЕННОСТИ ВЕГЕТАЦИИ, ЦВЕТЕНИЯ И ПЛОДОНОШЕНИЯ ВИДОВ РОДА SPIRAEA L. ПРИ КУЛЬТИВИРОВАНИИ НА ЕВРОПЕЙСКОМ СЕВЕРО-ВОСТОКЕ (РЕСПУБЛИКА КОМИ)}

(C) 2018

Смирнова Анна Николаевна, аспирант, ведущий инженер отдела Ботанический сад

Зайнуллина Клавдия Степановна, кандидат биологических наук, старший научный сотрудник отдела Ботанический сад

Институт биологии Коми научного ичентра УрО РАН (2. Сыктывкар, Российская Федерация)

Аннотащия. В статье рассматриваются вопросы цветения и плодоношения интродуцированных видов рода Spiraea L. в коллекции Ботанического сада Института биологии Коми НЦ УрО РАН, расположенного в 